\title{
System-cognitive analysis of the economic efficiency of mechanical fallow treatment based on data from the electronic book of field history
}

\author{
N.V. Stepnykh, S.D. Gilev, E.V. Nesterova*, and A.M. Zargaryan \\ FSBSI "Ural Federal Agrarian Research Center of the Ural Branch of the Russian Academy of \\ Sciences", 620142, city of Yekaterinburg, Belinskogo Str., 112A, Russia
}

\begin{abstract}
The article presents a differentiated for each field economic analysis of the use of agricultural tools in the processing of fallow fields, conducted using digital tools developed by the authors. Production data from the the Kurgan Research Institute of Agriculture, a branch of the FSBSI Ural Federal Agrarian Research Center of the Ural Branch of the Russian Academy of Sciences for 2017-2019. Based on information from the electronic book of field history, the program for calculating process charts calculates the cost of fallow mechanical treatment. Methods of system-cognitive and statistical analysis were used to review the results. It was found that the greatest impact on the increase in costs was exerted by the total number of treatments and the use of low-productivity agricultural tools (BDT-3. KPS-4.2). To increase the yield of wheat, a greater number of treatments of BDM-6-4 and a smaller number of treatments of KPE-3.8 and KPS-4.2 had some advantage. The total number of mechanical fallow treatments did not correlate with the wheat yield obtained for the next year, but it had an impact on the profitability of crop production. To reduce the cost of fallow treatment, it is recommended to use high-performance agricultural equipment BDM-6-4 and anti-erosion cultivators KPE-3.8 (2 in the coupling), aggregated by the energy-intensive tractor HTZ-17221.
\end{abstract}

\section{Introduction}

Accounting and control in modern agriculture is increasingly becoming digital: monitoring equipment using GIS technologies allows to take into account the history of each field, and special computer programs - to differentiate costs. In the conditions of the arid Trans-Urals, short-rotation grain-fallow crop rotations with the use of pure steam in the range of $25-33 \%$ play an important role in agriculture stabilization. Methods of fallow fields treatment affect the efficiency of cultivation of the subsequent crop, and costs make a significant contribution to the profitability of production.

Resource-saving treatment tools for surface treatment to a depth of 10-12 cm are widely used both in the world and in Russia. They also have an advantage in preserving moisture in arid conditions. For example, in Canada, resource-saving treatment, including minimal

*Corresponding author: kniish@ketovo.zaural.ru 
and zero, by the end of the 20th century occupied about two-thirds of the arable land area [1]. Due to the high risk of wind erosion, cultivators are used here even for basic treatment [2]. Countries with similar climatic conditions (Australia, Argentina, and the United States) followed the same path. Surface treatments are also popular in semi-arid regions of European countries [3]. Minimization of treatment is often accompanied by a reduction in the area of the steam wedge. Especially widespread non-fallow farming is being introduced on Kazakhstan lands [4]. However, some authors argue that shift away from steam is economically feasible, and the output per unit area in crop rotations is higher $[5,6]$; others, without denying the opinion of the former, reasonably prove that steam is the main guarantor of stable grain production, which also allows rational use of equipment and labor resources [7]. Mechanical steam remains the most common and more environmentally friendly. But the choice of the decision on the economic feasibility of a particular method of fallow fields treatment should be approached carefully and scientifically.

According to long-term research of Trans-Ural scientists, in modern agricultural technologies, the maximum profitability of spring wheat cultivation by steam precursor $(74.2 \%)$ is provided by a minimal system of steam preparation with surface cultivations [7]. This method of fallow treatment is currently most widespread in the Trans-Urals fields.

At the same time, the variety of soil and climate conditions, organizational factors, material, technical and resource base of agricultural enterprises can make significant adjustments to scientific recommendations. This is achieved by creating a database of field history, which allows to evaluate the advantages and disadvantages of agricultural practices used. In modern conditions, this is implemented using electronic books of field history, digital systems for accounting and control of agricultural technologies. This work takes place in thr Kurgan Agricultural Research Institute - Branch of FSBSI Ural Federal Agrarian Research Center of the Ural Branch of the Russian Academy of Sciences, where since 2017 a detailed account of field work in the context of each field is maintained. Data are entered in the electronic book of field history developed at the Institute (certificate No. $2018662258 \mathrm{dd} 20.07 .2018$ ), information is recorded on the type of crops, reproductions, equipment used, chemization means, dates of agricultural operations, yield [8].

Analysis of the effectiveness of agricultural practices in the fields is an important source of new knowledge on field production. However, it is often not possible to conduct an analysis using generally accepted statistical methods due to the lack of repetitions and heterogeneity of the data sample, a large number of options and factors affecting the effectiveness of agricultural practices, the number of which is significantly greater than in conducted scientific experiments. In this regard, the method of system-cognitive analysis developed by E.V. Lutsenko is of scientific interest, (KubSAU), which allows to transform the initial empirical data into information and with a high probability determines the most significant factors in terms of their influence on a particular parameter [9].

The objective of this research is to analyze the economic efficiency of fallow treatment in the context of fields. The task is to choose the optimal method of mechanical treatment in fallow fields with the lowest cost using system-cognitive analysis.

\section{Materials and methods}

Studies conducted in the central zone of the Kurgan region on the basis of production data of the Kurgan Research Institute of Agriculture, Branch of FSBSI Ural Federal Agrarian Research Center of the Ural Branch of the Russian Academy of Sciences for 2017-2019 in the laboratory of economy and innovative development within the framework of the State Assignment of the Ministry of Science and Higher Education in the direction Program 142 of the FSR of the state academies of sciences on the theme No. 0773-2020-0027 "To improve the system of adaptive-landscape agriculture in the Ural region and to create 
agricultural technologies of new generation based on the minimization of treatment, diversifying crop rotations, integrated plant protection, biologization, preserve and enhance of soil fertility and to develop information-analytical complex of computer programs and databases, ensuring innovative management of the farming system".

Fallow fields treatment in production areas of the institute is conducted according to the type of the early steam by minimum system: repeated (4-6 times) surface to a depth of 6-12 $\mathrm{cm}$ during the field season (from early June to late September) with various equipment depending on degree of infestation, weather conditions, and organizational capabilities. The first main treatment is carried out with disk tools (BDM-6-4, BDT-3), on separate fields with a seeder-cultivator SKP-2.1. In summer, cultivators KPE-3.8 and KPS-4.2 are used. Aggregation occurs with MTZ-80, K-700, and HTZ 17221 tractors.

All different technologies were numbered, technological charts and economic indicators were compiled and calculated using their own program "Designing technologies for growing crops" (certificate No. 2017617052 dd 3.11.2017). Options of different agricultural tools use are analyzed in the universal cognitive system "Eidos-X++", created by E.V. Lutsenko and located in the public domain at http://lc.kubagro.ru/aidos/.

\section{Results and Discussion}

The yield of spring wheat in 2018 and 2019 showed the economic effect of choosing a steam predecessor. Despite the fact that the profitability of grain production by steam, taking into account last year's costs, is significantly lower than without them (for example, in $2018,64 \%$ vs. $124 \%$ ), a higher yield on average for fields compared to the grain predecessor ( 2.41 vs. $1.75 \mathrm{t} / \mathrm{ha}$ in 2018 and $2.32 \mathrm{vs.} 1.86 \mathrm{t} / \mathrm{ha}$ ) allows to get additional profit and compensate for last year's costs. The profitability of production in 2018 for the grain predecessor was $20 \%$, for the steam one $-64 \%$, in 201970 and $72 \%$, respectively.

However, the analysis of data in the context of fields showed that the difference in yield varied significantly, including for steam predecessors: in 2018 from 1.3 to $3.3 \mathrm{t} / \mathrm{ha}$, in 2019 from 1.9 to $2.6 \mathrm{t} / \mathrm{ha}$, therefore, the profitability also changed (Fig. 1). The adjustments to the total cost included the cost of treatment of the fallow field in the previous year. 

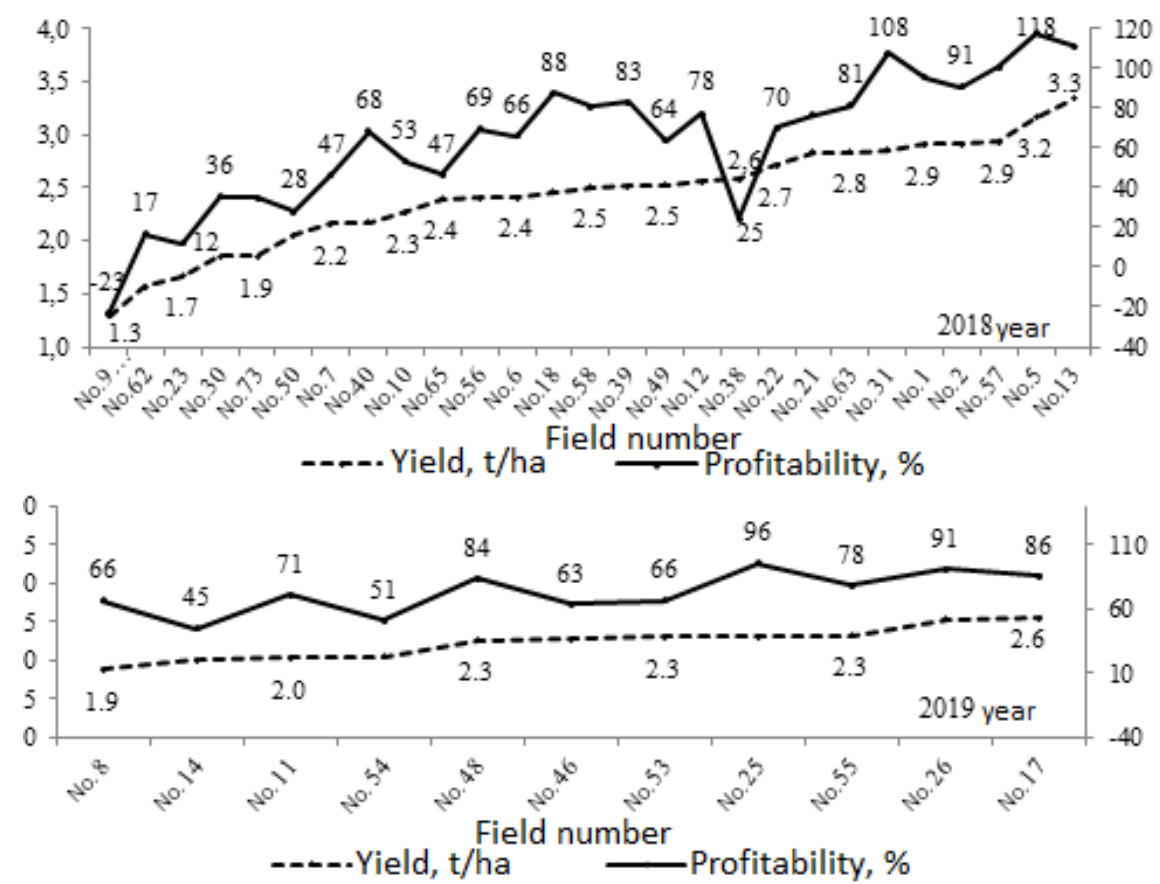

Fig. 1. Productivity and profitability of spring wheat cultivation in different fields (their number differed in different years) according to the steam predecessor, the Kurgan Agricultural Research Institute, 2018-2019.

In almost all fields, the combination of treatment methods differed in the number of treatments per field season (from 2 to 8) and the type of agricultural equipment (BDM-6-4, BDT-3, SKP-2.1, KPE-3.8, KPS-4.2), which primarily affected costs. With the increase in the number of treatments, the cost of 1 hectare treatment increased. So, the technology with 2 treatments with BDM-6-4 costs 1175 rubles, and with 5 treatments with different tools from 2837 to 3335 rubles, with 8 treatments -6254 rubles. However, this increase was not directly proportional.

To assess the impact on the total cost of tools used, the method of system-cognitive data analysis using the universal cognitive analytical system "Eidos-X++" was used. As a result, it was confirmed that the "total number of treatments 3/3" marker, which had the highest significance (10.500), had the greatest impact on the increase in costs for mechanical fallow fields treatment. The same level of significance had the marker "number of BDT-3 3/3 treatments". The addition to the "3/3" marker characterizes the group corresponding to the maximum values (in the latter case, from 1.7 to 2 BDT-3 treatments). The "number of KPS4.2 treatments $3 / 3$ " marker has a slightly lower but rather high significance (6.667) (Table $1)$.

Table 1. Information portrait of classes, where (3/3) - the highest, $(1 / 3)$ - the lawest, $(2 / 3)$ the average costs in the context of various interval values of markers (the number of treatments with different agricultural tools)

4.2.1. Information portraits of classes

Information portrait of classes:3 "Fallow treatment costs-3/3-(4561.0000000, 6254.0000000)" in model:8 "INF5"

\begin{tabular}{|l|l|l|l|l|}
\hline Code & Class name & Code & Marker name & Value \\
\hline
\end{tabular}




\begin{tabular}{|l|l|l|l|c|}
\hline 1 & $\begin{array}{l}\text { Fallow treatment costs-1/3- } \\
(1175.000 \ldots\end{array}$ & 6 & $\begin{array}{l}\text { Number of treatments BDT-3/3- } \\
(1.6666667,2.0000000)\end{array}$ & 10.500 \\
\hline 2 & $\begin{array}{l}\text { Fallow treatment costs-2/3- } \\
(2868.000 \ldots\end{array}$ & 15 & $\begin{array}{l}\text { Total number of treatments-3/3- } \\
(6.0000000,8.0000000)\end{array}$ & 10.500 \\
\hline 3 & $\begin{array}{l}\text { Fallow treatment costs-3/3- } \\
(4561.000 \ldots\end{array}$ & 12 & $\begin{array}{l}\text { Number of treatments KPS-3/3- } \\
(3.6666667,5.0000000)\end{array}$ & 6.667 \\
\hline & 4 & $\begin{array}{l}\text { Number of treatments BDT-1/3- } \\
(1.0000000,1.3333333)\end{array}$ & 1.300 \\
\hline
\end{tabular}

In fact, the technologies that used treatments with BDT-3 disk harrows aggregated by MTZ-80, with a total cost of agricultural operations of $901 \mathrm{rubles} / \mathrm{ha}$, turned out to be inefficient, despite the lower cost of the tractor and the named agricultural machines compared to BDM-6-4, whose stubble field disk harrowing when aggregated with K-700 or HTZ 17221 costs 603 and 487 rubles/ha. The same can be said about the use of a stubble seeder-cultivator SKP-2.1 with MTZ-80 (cost 721 rubles/ha). Cultivation of soil using KPS-4.2 with MTZ-80 - less expensive agricultural practice - 523 rubles/ha, but also the least productive and efficient.

The correlation coefficient of the total number of mechanical treatments and wheat yield in these fields was -0.04 , which is quite logical, since the yield of spring wheat sown under various fallow treatment options is influenced by many other factors, such as agrochemical indicators of soil, variety, sowing time, etc.

When considering fields with a single wheat variety, the relationship with the number and types of agricultural tools used in treatment of steam precursor was also not established. For example, the most widely presented options for mechanical treatments in fields with the Raduga variety, which was sown using technologies with stubble and disc seeders, were analyzed (table 2).

At the maximum number ( 8 times) of mechanical treatments in the fallow field No. 38 , the wheat yield was $2.58 \mathrm{t} / \mathrm{ha}$, which is higher than the average among fields with the SKP2,1 seeder, but less than in field No. $1(2.91 \mathrm{t} / \mathrm{ha})$ with 6 treatments, and the cost of this number of treatments was 1.5 times higher, the profitability at the same level of yield with field No. $39(2.58 \mathrm{t} / \mathrm{ha}$ and $2.51 \mathrm{t} / \mathrm{ha})-3$ times lower. With 5 mechanical treatments on fields No. 30 and No. 39, the yield differed by $0.66 \mathrm{t} / \mathrm{ha}$ in favor of field No. 39. It was assumed that the influence of the soil potential on the field is higher than the fallow treatment method. It turned out that the humus content in field No. 39 according to field surveys is $4.3 \%$, in field No. $30-3.1 \%$.

In the fields with sowing with the SZ-5,4 seeder with the same amount and type of fallow treatment and the same technology of wheat cultivation in fields No. 22 and No. 23, the grain yield differed by $1.04 \mathrm{t} / \mathrm{ha}$ in favor of No. 23. The microrelief and soil potential (humus content $2.9 \%$ vs. 2.6) probably had a positive impact on this field, as well as on field 21 (humus content $3.7 \%$ ).

Table 2. Economic efficiency of production of Raduga spring wheat grain depending on fallow treatment technology in different fields, the Kurgan Agricultural Research Institute, 2018-2019

\begin{tabular}{|c|c|c|c|c|c|c|c|c|c|c|c|}
\hline $\begin{array}{c}\text { Field } \\
\text { No. }\end{array}$ & 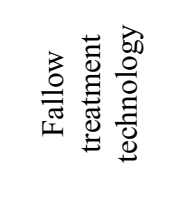 & 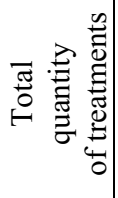 & 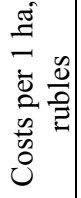 & 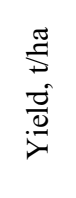 & 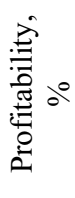 & $\begin{array}{l}0 \\
z \\
0 \\
0 \\
0\end{array}$ & 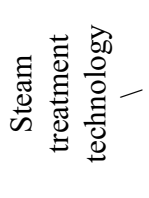 & 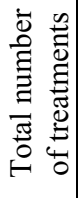 & 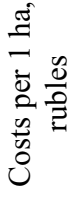 & 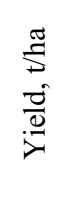 & 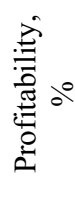 \\
\hline \multicolumn{6}{|c|}{$\begin{array}{c}\text { Date of sowing 16-22.05.2018., } \\
\text { seeder SKP-2.1, date of harvesting 2-8.09.2018. }\end{array}$} & \multicolumn{6}{|c|}{$\begin{array}{c}\text { Date of sowing 9-13.05.2018., seeder SZ-5.4, } \\
\text { date of harvesting 24.08.-8.09.2018. }\end{array}$} \\
\hline 1 & $\begin{array}{l}\text { Mech. fallow } \\
7\end{array}$ & 6 & 3959 & 2.91 & 97 & 21 & $\begin{array}{l}\text { Mech. } \\
\text { fallow } 4\end{array}$ & 5 & 3271 & 2.84 & 79 \\
\hline
\end{tabular}




\begin{tabular}{|c|c|c|c|c|c|c|c|c|c|c|c|}
\hline 30 & $\begin{array}{c}\text { Mech. fallow } \\
11\end{array}$ & 5 & 3548 & 1.85 & 37 & 22 & $\begin{array}{c}\text { Mech. } \\
\text { fallow 2 }\end{array}$ & 5 & 3672 & 2.71 & 71 \\
\hline 38 & $\begin{array}{c}\text { Mech. fallow } \\
15\end{array}$ & 8 & 6254 & 2.58 & 26 & 23 & $\begin{array}{c}\text { Mech. } \\
\text { fallow 2 }\end{array}$ & 5 & 3672 & 1.67 & 13 \\
\hline 39 & $\begin{array}{c}\text { Mech. fallow } \\
3\end{array}$ & 5 & 3238 & 2.51 & 85 & & - & - & - & - & - \\
\hline Av. & - & - & - & 2.46 & - & Av. & - & - & - & 2.41 & - \\
\hline \multicolumn{7}{|c|}{$\begin{array}{c}\text { Date of sowing.17-19.05.2019., } \\
\text { seeder SKP-2.1, date of harvesting 3-12.09.2019. }\end{array}$} & \multicolumn{2}{|c|}{$\begin{array}{c}\text { Date of sowing 2-6.05.2019., seeder SZ-5.4 } \\
\text { date of harvesting 15-19.08.2019. }\end{array}$} \\
\hline 17 & $\begin{array}{c}\text { Mech. fallow } \\
22\end{array}$ & 5 & 3307 & 2.55 & 86 & 46 & $\begin{array}{c}\text { Mech. } \\
\text { fallow 20 }\end{array}$ & 4 & 2705 & 2.27 & 63 \\
\hline 26 & $\begin{array}{c}\text { Mech. fallow } \\
23\end{array}$ & 5 & 3468 & 2.54 & 91 & 48 & $\begin{array}{c}\text { Mech. } \\
\text { fallow 19 }\end{array}$ & 4 & 2649 & 2.26 & 84 \\
\hline 55 & $\begin{array}{c}\text { Mech. fallow } \\
19\end{array}$ & 4 & 2649 & 2.32 & 78 & 53 & $\begin{array}{c}\text { Mech. } \\
\text { fallow 21 }\end{array}$ & 4 & 2617 & 2.30 & 66 \\
\hline- & - & - & - & - & - & 54 & $\begin{array}{c}\text { Mech. } \\
\text { fallow 21 }\end{array}$ & 4 & 2617 & 2.05 & 51 \\
\hline Av. & & & & $\mathbf{2 . 4 7}$ & - & Av. & & & & $\mathbf{2 2 . 2}$ & \\
\hline
\end{tabular}

The types of agricultural tools used did not have a significant impact on the yield. At the same time, the analysis in the "Eidos-X++" system showed some advantage of the options where there were more BDM-6-4 treatments (the significance at the "3/3" level was 0.759) and fewer KPI-3.8 and KPS-4.2 treatments (the significance at the "1/3" level -0.583 and 0.539 , respectively).

\section{Conclusion}

1. The analysis of the production data of the Kurgan Agricultural Research Institute fields showed an advantage in economic efficiency of the steam predecessor compared to the grain one, the costs of last year's mechanical fallow treatment are compensated by an increase in the yield.

2. The obvious differences in costs for the options for using different agricultural implements, associated with an increase in the frequency of treatments and the use of different types of equipment, have been established.

3. As a result of the system-cognitive analysis, it was confirmed that the increase in the cost of processing the fallow field is associated with the total number of treatments and the use of low-productivity agricultural equipment BDT-3.

4. Differences in the number of mechanical treatments in a fallow field and types of agricultural implements did not significantly affect the yield of spring wheat. Analysis in the universal cognitive system "Eidos-X++" showed some advantage of a larger number of BDM-6-4 treatments and a smaller one - with KPE-3.8 tools aggregated by HTZ-17221 or K-700, and KPS-4,2 with MTZ-80.

5. Differences in the cost of each treatment were reflected in the profitability of grain production. To reduce the cost of fallow treatment, the most appropriate methods of mechanical treatment in fallow fields were the use of high-performance agricultural tools BDM-6-4, as well as the anti-erosion cultivator KPE-3.8 (2 in the coupling), aggregated by the HTZ 17221 tractor. As a result of system-cognitive analysis, these options were the most economically optimal among the studied options. 


\section{References}

1. G. Padbury, S. Waltman, J. Caprio, G. Coen, S. McGinn, D. Mortensen, G. Nielsen, R. Sinclair. Agronomy Journal, 94(2), 251-261 (2002)

2. B.G. McConkey, C.A. Campbell, R.P. Zentner, H. Peru, A.J. Vandenbygaart. Effect of treatment and cropping frequency on sustainable agriculture in the Brown Soil Zone, Prairie Soils and Crops, 5, 42-50 (2012)

3. J.J. Lampurlanes, P. Angas, C. Cantero-Martinez. Soil \& Treatment Research, 65, 2, 207-220 (2002)

4. M.K. Syleimenov, Z.A. Kaskarbayev, K. Akshalov. Development of treatment theory in Northern Kazakhstan, Science News of Kazakhstan, 1, 115-123 (2015)

5. A.N. Suhov, Net steam: 0 or 50\%? Izvestia of the Lower Volga Agro-University Complex, Science and higher professional education, 1(5), 28-35 (2007)

6. A.A. Ageev, Yu.B. Anisimov, A.V. Vrazhnov, E.L.Kalyuzhina. Agricultural Journal, 3, 17-22 (2019)

7. V.A. Telegin, S.D. Gilev, I.N. Cymbalenko, O.S. Bastrychkina. Agrarian Bulletin of the Urals, 7(113), 12-14 (2013)

8. N.V. Stepnyh, A.M. Zargarjan, E.V. Nesterova. Journal of New Economy, 4, 136-146 (2018)

9. E.V. Lutsenko. Industrial laboratory. Diagnostics of materials, 81(5), 61-71 (2015) 